DOI 10.20396/ideias.v8i2.8650130

\title{
Beco sem saída ou ponto de partida?: a ilusão biográfica e os historiadores ${ }^{1}$
}

\author{
Vinicius Alves do Amaral ${ }^{2}$
}

\begin{abstract}
Resumo: Apesar do interesse por histórias de vida ser antigo, a sociedade contemporânea tem requisitado cada vez mais obras do gênero. Contudo, profundas transformações no pensamento ocidental nas últimas décadas repercutiram nos princípios e métodos das biografias. Nosso propósito no presente ensaio é compreender os principais termos desse debate através da literatura e quais seus reflexos para uma classe intelectual específica, os historiadores.
\end{abstract}

Palavras-chave: Biografia. Literatura. História.

\section{Dead-end or starting point? The biographical illusion and Historians}

Abstract: Although the interest in life stories is ancient, contemporary society has required increasingly works of the genre. However, profound changes in Western thought in the last decades have affected the principles and methods of biographies. Our purpose in this essay is to understand the key terms of this debate through literature and its effects to a specific intellectual class, the historians.

Keywords: Biography. Literature. History.

¿Callejón sin salida o punto de partida? La ilusión biográfica y los historiadores

Resumen: Aunque el interés en las historias de vida es antiguo, la sociedad contemporánea ha exigido cada vez más obras de este tipo. Sin embargo, transformaciones profundas en el pensamiento occidental en las últimas décadas han tenido impacto en los principios y métodos de las biografías. Nuestro propósito en el presente ensayo es comprender los principales términos de este debate a través de la literatura y cuáles son sus implicaciones para una clase intelectual específica, los historiadores.

Palabras-clave: Biografía. Literatura. Historia.

\footnotetext{
${ }^{1}$ Recebido em 16/08/2016 e aprovado em 23/03/2017.

${ }^{2}$ Doutorando em História pela Universidade Federal Fluminense (UFF) e pesquisador do Laboratório de História Oral e Audiovisual da Universidade Federal do Amazonas (UFAM). Contato: viniciuscarqueija@gmail.com.
} 
$|220|$

Beco sem saída ou ponto de partida?...

Eu nem atinava com isso de ser um eu e até que tudo ia muito bem, obrigado, antes que o mundo passasse a desabar em torno de mim, tal e qual me parece, agora, o mundo, sem mais nem menos, um novelo de eus, todos feitos de talvez.

\section{(Aldísio Filgueiras)}

\section{Introdução}

Uma das mais flagrantes contradições da sociedade contemporânea centra-se justamente na questão das representações do "eu": enquanto nos mais diferentes suportes de mídia o culto ao indivíduo adquire um vulto cada vez maior, a Literatura ainda se vêàs voltas com a morte do autor, ou seja, com a despersonalização do eu.

A partir de 1970 um grupo de destacados filósofos da linguagem (dentre eles Roland Barthes, Michel Foucault, Gilles Deleuze e Jacques Derrida) passou a esposar a tese de que o autor não deve ser a única chave de compreensão do texto, deslocando assim os olhares para o leitor e suas possíveis interpretações dos discursos (GAGLIARDI, 2010, p. 288).

Não por acaso estes intelectuais estavam empenhados na revisão do conceito moderno de sujeito. Michel Foucault manifestou muito bem esse intento no trecho abaixo:

Seria interessante tentar ver como se dá, através da história, a constituição de um sujeito que não é dado definitivamente, que não é aquilo a partir do que a verdade se dá na história, mas de um sujeito que se constitui no interior mesmo da história, e que é a cada instante fundado e refundado pela história. É na direção dessa crítica radical do sujeito humano pela história que devemos nos dirigir (FOUCAULT, 2005, p. 10).

Foucault (2014, p. 16-17) procurou analisar as diferentes formas em que o sujeito foi apreendido pelos enunciados 
discursivos e encontrou em obras da Antiguidade Clássica (correspondências, obras literárias e filosóficas) uma proposta alternativa à concepção unitária e homogênea de sujeito forjada pela modernidade. Por sua vez, Deleuze (1997, p. 13) encontrou na Literatura, especialmente aquela que foge do cânone da identidade nacional, um rico antídoto ao encarceramento do sujeito numa categoria fixa e monolítica.

Não foi apenas a Filosofia que encontrou na Literatura uma importante interlocutora. Giovanni Levi lembra que a historiografia assistiu nos últimos anos a um rico diálogo com a Literatura no qual a biografia foi um dos seus canais privilegiados. O pesquisador italiano credita aos escritores a responsabilidade por abrir os olhos dos historiadores para questões teóricas e metodológicas até então negligenciadas, como a racionalidade anacrônica das narrativas biográficas tradicionais e o lugar da interpretação crítica na escrita de histórias de vidas (LEVI, 2002, p. 168). No presente ensaio pretendemos abordar estes dois pontos a partir de duas experiências literárias distintas.

\section{Nos rastros de Fraga e Mundo}

Os passos no rastro, conto do escritor argentino Júlio Cortázar, basicamente trata das consequências de um biógrafo que ao buscar ser imparcial acaba se tornando extremamente tendencioso. Cansado da obscuridade que envolvia seu poeta preferido, o professor universitário Jorge Fraga lança-se numa pesquisa sobre Cláudio Romero. Nesse processo encontra numa vila distante a filha de um dos maiores amores do poeta portenho, a normalista Suzana Márquez. Por meio da correspondência trocada com Márquez, Fraga consegue restituir a fase mais sombria da vida de Romero: seus últimos anos de vida.

Em 1917, portanto, ele conheceu num baile a jovem normalista. Ao final do mesmo ano, contudo, buscou convencê-la nas cartas a largar-lhe. Ele já tinha então contraído tuberculose. Não quer que ela tenha o fardo de se casar com um moribundo. 
| 222 |

Beco sem saída ou ponto de partida?...

Exilando-se na solidão, Romero ainda desejava ter uma paixão impossível antes de partir. Encontrou na bela e rica Irene Paz sua última musa e lhe dedica seu poema mais famoso, Ode ao teu nome duplo.

A vida de um poeta argentino torna-se sucesso de crítica, garantindo ao seu autor prêmios e até mesmo possíveis cargos diplomáticos. Porém, no auge da consagração de seu livro algo passa a lhe inquietar no conteúdo daquelas cartas. Tentando confirmar uma suspeita confronta mais uma vez a descendente de Suzana Márquez. Esta lhe revela, enfim, uma última carta onde o tratamento do poeta para com sua amada não poderia ser mais humilhante.

Uma nova interpretação surge para as atitudes de Romero: diante da possibilidade de contrair matrimônio com uma filha da aristocracia local (Irene Paz), o poeta enxota a pobre Suzana Márquez de sua vida. Ela, desesperada, se entrega à prostituição. Só tempo depois pode sair do submundo de Buenos Aires pelas mãos de um militar, com o qual casou. Quanto a Romero, talvez seus planos tenham sido descobertos pela família de Irene. Seu "triunfo fácil" não veio, mas a glória sim, mas somente após a sua morte. E Fraga contribuiu sobremaneira para a canonização do autor de Ode ao teu nome duplo.

Cada vez que eu tinha de escolher, decidir sobre a conduta daquele homem, escolhia o reverso, o que ele pretendia fazer acreditar enquanto estava vivo. Minhas escolhas eram as dele, quando qualquer um teria podido decifrar outra verdade em sua vida, em suas cartas, naquele último ano em que a morte o ia encurralando e despindo (CORTÁZAR, 2011, p. 35).

O interessante é que Fraga, professor medíocre e frustrado, fez de seu livro sua própria Irene Paz. A biografia lhe abriu as portas para o sucesso, ainda que às custas de uma omissão terrível. Como resultado da crise de consciência que enfrenta, Jorge Fraga desconstrói o ídolo dos poetas portenhos na cerimônia 
de entrega do Prêmio Nacional. Agora, como Romero, via seu plano sabotado, mas por si próprio.

O grande desfecho do conto é descobrirmos que há muito de Cláudio Romero em Jorge Fraga. Por ventura há algo de Romero ou Fraga em Cortázar? Trata-se de uma questão delicada. É possível dizer que Cortázar teve uma trajetória discreta enquanto professor acadêmico e colaborador literário até 1951, quando publicou o livro Bestiário e mudou-se para Paris. Na capital francesa passou a atuar como tradutor da UNESCO (CARVALHO, 2014, p. 51-54).

Mário Vargas Llosa, colega de trabalho de Cortázar, em um artigo recente para o jornal El País confessa que entre os anos 60 e 70 o amigo passou por uma transformação radical: o comedido escritor, já cinquentão, divorciara-se de sua esposa Aurora e engajara-se mais em assuntos políticos e sexuais (VARGAS LLOSA, 2014). Tais mudanças seriam um meio de escapar de um roteiro previsível de vida, de um "triunfo fácil"? $\mathrm{Na}$ falta de um estudo aprofundado sobre este tópico, a questão fica no terreno das conjecturas.

Os passos no rastro pertence a essa fase tardia da vida do escritor. O conto faz parte do livro Octaedro, publicado em 1974 (o autor faleceria dez anos depois). As histórias continuam sendo bem delimitadas, configurando microcosmos humanos, mas em Octaedro a incidência do fantástico é menor que em seu primeiro livro de contos, Bestiário. Uma boa prova é a sóbria saga de Jorge Fraga. Um contraponto à experiência de Fraga pode ser encontrado em Cinzas do Norte. No romance do escritor amazonense Milton Hatoum, Olavo busca relembrar a evolução de sua amizade com (Rai)Mundo. Desde os tempos de estudante no Colégio Estadual, Mundo demonstrava talento artístico e um ressentimento profundo que no decorrer dos anos se combinaram de um modo trágico.

Mundo esforça-se para apreender a um só tempo a dinâmica da arte e do ambiente que o cerca (a Amazônia). Assim, a descrição do seu quarto se assemelha muito a de um laboratório: "Folhas 
de papel, pincéis, lápis, tubos de tinta, penas de pássaros, plantas ressequidas e sementes espalhados no chão; num cubo de vidro, cipós enrolados em forma cônica, e, nas paredes, desenhos com símbolos indígenas" (HATOUM, 2010, p. 24).

Em meio a esse processo de descoberta ele se aproxima de duas figuras que estão ligadas com o passado de sua mãe, Alícia: o radialista Ranulfo, tio de Olavo, e o artista plástico Alduíno Arana. Mas aos poucos, Mundo passa a se distanciar do último, pois deseja realizar algo mais ousado, como as intervenções artísticas que vinham sendo experimentadas no Rio de Janeiro e São Paulo na época.

A opção pela arte que desarma as certezas também o coloca em rota de colisão com os desejos de seu pai, Trajano, rico empresário de Manaus. Instala-se então um círculo vicioso de frustrações entre o pai, a mãe e o filho, sendo Olavo um observador privilegiado destas tensões por ser sobrinho da costureira da família Mattoso.

Para desafiar o pai, Mundo aceita entrar no Colégio Militar, ocupando seus dias com treinamentos de sobrevivência na selva e porres nos bares. No entanto, a rotina escondia ainda o espírito sagaz e inquieto do rapaz que em seu diário registrava as contradições do Brasil Grande defendido pela Ditadura Militar:

O tenente jurava que um general do Comando Militar da Amazônia ia ser presidente do Brasil... A maioria dos alunos do internato é cobaia. Ainda não mexeram comigo, meu pai é conhecido no Gabinete do Comando. Com os outros internos é diferente (HATOUM, 2010, p. 129).

Inconformado com o que vinha acontecendo tanto dentro quanto fora dos quartéis, Mundo planeja uma intervenção artística com a ajuda de Ranulfo que desagradaria profundamente os militares, comprometendo inclusive a imagem do seu pai perante eles.

Chamada de Campo de Cruzes, a intervenção consistia em comparar o novo bairro construído pelo prefeito com um cemitério, espalhando cruzes e cinzas pelas ruas de barro 
numa crítica ao mórbido projeto de urbanização que prosperou em Manaus após a implantação da Zona Franca em 1967.

A própria forma como o fato foi noticiado demonstrava o quão comprometido estavam os principais veículos da imprensa local:

\begin{abstract}
A matéria, em sua maior parte um resumo elogioso da biografia de Jano, ironizava a pretensão de Mundo: "um filho rebelde, estudante fracassado e dândi fardado que queria fazer arte contemporânea num bairro de gente pobre, onde quase todos são analfabetos" (HATOUM, 2010, p. 132).
\end{abstract}

A notícia reduz toda a complexa existência de Mundo a alguns adjetivos: rebelde e fracassado. No cerne dessa oposição entre a biografia sólida de Jano e o arremedo de história de vida de Mundo está uma concepção de História tradicionalista, extremamente comprometida com os poderosos.

Os militares perseguem todos os envolvidos no evento, agredindo gravemente Ranulfo. Mundo decide vingar o amigo confrontando o próprio pai que vem a falecer. Para esquecer o ocorrido o rapaz é mandado para o exterior e sua mãe vai viver no Rio de Janeiro. De volta ao Brasil, Mundo sente-se assombrado por seus demônios. Após um protesto apanha tanto da Polícia que precisa ser hospitalizado.

Dias antes de morrer, Mundo confessaria em carta a Olavo que pensava em reescrever a sua vida, mas que naqueles instantes finais "se sentia menos que uma voz" (HATOUM, 2010, p. 230). Quem se lança inicialmente no empreendimento biográfico é o tio de Olavo, Ranulfo. Tio Ran encarrega seu sobrinho de publicar seu relato, mas Olavo guarda os papéis por muito tempo. Quando decide lançá-los a lume acaba acrescentando também suas memórias sobre Mundo.

Como Olavo, Milton Hatoum também esperou um bom tempo para publicar seu romance. Esboçou a ideia na década de 1970, quando já tinha deixado Manaus para estudar em Brasília. 
$|226|$

Beco sem saída ou ponto de partida?...

Só em 2005, depois de ter se formado em Arquitetura, de lecionar em algumas universidades e de ter publicado dois romances ganhadores do Prêmio Jabuti de Literatura (respectivamente, Relato de um certo Oriente e Dois Irmãos), só então ele finalmente deu a forma definitiva a Cinzas do Norte (LEAL, 2010, p. 111-112).

O distanciamento, tanto temporal quanto espacial (Hatoum mora em São Paulo há mais de 30 anos), está associado à própria dinâmica da reconstituição memorialística a serviço da Literatura. Para Hatoum a matéria prima da Literatura deve ser a imaginação, claro, ancorada nas experiências sociais. Portanto, sua relação com a Antropologia (podemos estender a discussão às Ciências Humanas, uma vez que nesse texto o escritor discute a relação entre a narrativa científica e ficcional) se define por "uma forma peculiar de parentesco ou algum tipo de afinidade", pois ainda que estabeleça uma ponte com a realidade, a Literatura também se propõe a ser um discurso sobre o Outro (HATOUM, 2005, p. 83). Discurso esse que estimula a alteridade, na medida em que permite ao leitor compreender o Outro e a si mesmo.

Cortázar também abordou a tensão entre a ficção e a ciência, especialmente a ciência histórica. Para ele, tanto a Literatura quanto a História tinham o mesmo objeto de interesse, o homem. Uma se dedica a reconstruir o homem no passado e a outra o homem no presente (embora Cortázar admita que muitos romances históricos sejam eficientes), porque esta deseja entrar em contato com algo mais vivo:

Por isso, e uma vez que Narciso continua sendo a imagem mais cabal do homem, a literatura organizase em torno de sua flor falante, e se empenha (está nisso) na batalha mais difícil e caprichosa de sua conquista: a batalha pelo indivíduo humano, vivo e presente, vocês e eu, aqui, agora, esta noite, amanhã (CORTÁZAR, 2006, p. 62-63).

Assim, a alteridade também é reconhecida por Cortázar como um traço comum à História e a Literatura (no entanto, vista como muito mais presente nesta última), mas o escritor 
também enuncia outra característica compartilhada por ambas: o desafio da linguagem. A dificuldade de dominar a "reconstrução total" da realidade, ou seja, traduzi-la em palavras. Para Cortázar, a missão de compreender o Outro, codifica-lo num texto, fez da problematização das palavras e das narrativas a raiz do fazer literário contemporâneo (CORTÁZAR, 2006, p. 66).

O mito da imparcialidade, a importância do exercício da alteridade e o reconhecimento da insuficiência da linguagem são pontos levantados por Cortázar e Hatoum de forma sagaz em suas obras, o que justifica a escolha dos nomes desses literatos para iniciar uma breve introdução ao desafio biográfico. Contudo, suas narrativas não ilustram apenas as questões que serão abordadas a seguir, elas também apontam para o grande caráter crítico que cerca o fazer literário. Nesse sentido, a Literatura pode ser mais que uma simples fonte para o historiador. Pode ser também uma valiosa ferramenta, ora sugerindo caminhos, ora oferecendo soluções narrativas.

\section{Uma fábula contemporânea}

Voltemos uma vez mais ao conto de Cortázar. A grande ironia é que Fraga evita desde o início fazer uma "autobiografia dissimulada". O conto pode, portanto, ser tomado como uma fábula na qual a moral da história seria a falência do observador imparcial. Esse personagem está associado ao que teóricos chamaram de biografia romântica. Os principais praticantes dessa variedade biográfica, em oposição à forma de biografia consagrada por Plutarco e Suetônio na Antiguidade Clássica, procuravam apresentar a vida das pessoas (geralmente grandes personagens) em minúcias e sem ofertar qualquer julgamento ético sobre suas ações (DOSSE, 2009, p. 161).

Evidente que o biógrafo enquanto observador imparcial oferecia aos leitores a confiança de estarem diante de uma narrativa extremamente verídica, acima das paixões que podem enuviar 
| 228 |

Beco sem saída ou ponto de partida?...

os recantos de uma vida. Tratava-se, como Fraga descobriu, de uma ilusão. Na década de 1970, Pierre Bourdieu chegava à mesma conclusão. Para ele, tratava-se de uma dupla ilusão porque admite que a existência em si irredutível possa ser enclausurada num sentido e que há uma oposição entre o indivíduo e a sociedade (BOURDIEU, 2002, p. 190).

Bourdieu assinalava a impotência da descrição unitária de uma vida presente em signos tão habituais aos indivíduos que são absorvidos acriticamente até pelos pesquisadores sociais: o nome, a assinatura, a posição social, etc. Poderia um nome dizer tudo sobre uma pessoa? Títulos como "industrial" ou "artista" não ofuscam outras dimensões de uma vida, afinal é possível ser artista ou industrial o tempo todo?

Para Bourdieu, o nome é o primeiro passo na individualização, processo encetado pelo Estado para contar com uma descrição oficial das pessoas. Assim, a certidão de identidade garante a existência social e essa, um leque de possibilidades de postos. Mas tudo começa com uma classificação oficial do indivíduo.

Foucault alertou em seus estudos justamente para a finalidade coercitiva na construção do indivíduo enquanto sujeito de conhecimento, principalmente nas ciências e no ordenamento jurídico. Pronunciar-se e ser compreendido decorria não só da capacidade de concatenar frases, mas da legitimidade do falante (FOUCAULT, 1999, p. 19). Para Foucault, os jogos de verdade se aprofundaram tanto que seria necessário realizar uma revisão das ciências.

Ao contrário de Foucault, que encontrou na própria epistemologia da ciência moderna um fator pernicioso à compreensão dos sujeitos, Bourdieu critica as noções absorvidas pelos pesquisadores sociais sem o crivo analítico. Tais noções, como a biografia tradicional, irradiaram de campos menos comprometidos com a cientificidade, como o senso comum.

A Literatura também está inscrita nesse rol, especialmente os romances. Consolidando no século XIX como gênero literário essencialmente moderno e burguês, o romance privilegiava 
uma narrativa linear e personagens transparentes. Sob este último aspecto, o poeta José Paulo Paes Neto esclarece:

\begin{abstract}
Diferentemente da opacidade das pessoas reais, a cujo íntimo só temos acesso por via conjuntural, as personagens de ficção são permeáveis ao nosso olhar. Ademais, os traços de que o romancista se vale para lhes desenhar os caracteres governam-se por uma economia expressiva onde não há lugar para impertinência: cada ação, cada palavra, cada cena, mesmo que pareça anódina, traz a sua carga de informação ou sugestão (PAES, 1999, p. 24).
\end{abstract}

Contudo, Bourdieu identificou uma mudança de paradigma no seio do próprio romance a partir do século XX. O pesquisador cita Som e Fúria de William Faulkner e ampara-se nas considerações de Allain Robbe-Grillet, autor de O Ano Passado em Marienbad. Diz ele ainda:

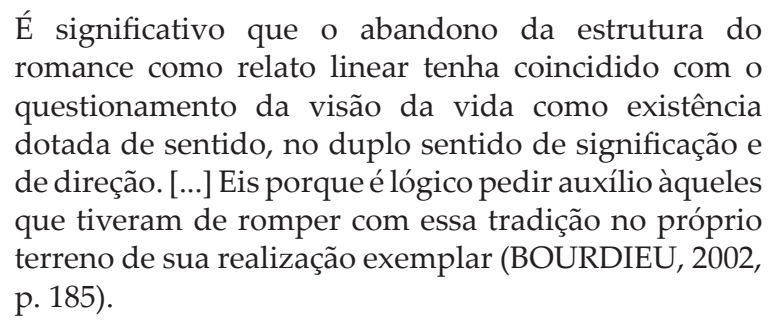

Porém, o sociólogo francês se absteve de trabalhar com os relatos do e sobre o sujeito biografado por fornecerem informações valoradas. No lugar da biografia, sugeriu que se utilizasse uma análise mais crítica da caminhada social das pessoas:

Ela conduz à construção de uma noção de trajetória como série de posições sucessivamente ocupadas por um mesmo agente (ou um mesmo grupo) num 
$|230|$

Beco sem saída ou ponto de partida?...

espaço que ele é próprio um devir, estando sujeito a incessantes transformações (BOURDIEU, 2002, p. 189).

François Dosse (2009, p. 209) enxerga em suas palavras uma clara invalidação do sujeito enquanto fonte de conhecimento histórico. Convém perguntar qual o mal de se trabalhar com as representações das pessoas se o próprio afirma em outra oportunidade que seu método (denominado por ele como "estruturalismo genético") se baseia na ideia de que

análise das estruturas objetivas - as estruturas de diferentes campos - é inseparável da análise da gênese, nos indivíduos biológicos, das estruturas mentais (que são em parte produto da incorporação das estruturas sociais) e da análise da gênese das próprias estruturas sociais (BOURDIEU, 2004, p. 26).

De fato, como aponta Roger Chartier, suas interpretações sobre a dinâmica artística sabem conciliar uma física social com uma fenomenologia social, aliando um olhar sobre as posições que as pessoas ocupam na sociedade com as representações que elas fazem de si (CHARTIER; LOPES, 2002, p. 150151). Contudo, quando se debruçou especificamente sobre os indivíduos, Bourdieu optou por minimizá-los diante das determinações sociais. Talvez essa seja uma característica de sua produção mais tardia ${ }^{3}$.

3 Esboço de uma teoria da prática foi publicado em 1972. A ilusão biográfica veio à tona em 1986 na revista Actes de la recherche em Science Sociales (fundada e dirigida por ele próprio desde 1975) e Esboço de autoanálise, o livro mais pessoal de Bourdieu, foi publicado em 2001, um ano antes de sua morte. Nestas três obras se encontram as maiores impugnações críticas de Bourdieu à biografia e ao indivíduo como fonte de valor heurístico. A partir de meados da década de 1970, o sociólogo francês se lança a uma teoria dos campos que objetivava substituir a visão de luta de classes, que em seu entendimento tornou-se anacrônica. Esse olhar para a configuração de um sistema global justificaria seus contundentes ataques à biografia? Curiosamente, também é a partir desse 
Concentrando-se ainda que brevemente na argumentação de Bourdieu, Sabina Loriga defende que:

\begin{abstract}
Todo o raciocínio é fundado sobre uma precisa, ainda que implícita, tripartição hierárquica entre o desprezível senso comum, o tradicional discurso romântico e a moderna vanguarda. Os dois primeiros seriam ainda prisioneiros da ilusão biográfica, enquanto que o terceiro teria, finalmente, eliminado as noções de sentido, sujeito e consciência. Como já disse, penso que Bourdieu deforma profundamente a reflexão dos grandes romancistas da virada do século XX (LORIGA, 2014, p. 258).
\end{abstract}

Para a historiadora italiana, o sociólogo francês ficou aferrado a uma leitura demasiado literal do discurso de autores vanguardistas, que, como tal, carregam nas tintas para poder ampliar o poder de sua ruptura com o passado. Embora concorde com um auxílio da Literatura de vanguarda, Bourdieu não busca nela técnicas ou estilos. A ele interessa apenas uma concepção do indivíduo e da narrativa, que se aos autores serviu como permissão para experimentar novos modos de narrar, para ele funciona como um interdito a tais práticas no âmbito da escrita biográfica.

Preocupado em estabelecer novos parâmetros para uma ciência do social, Bourdieu diverge de Foucault, pois entende que um mergulho mais demorado nos processos subjetivos de construção do indivíduo possa corromper a cientificidade da pesquisa. Seja como for, suas palavras sobre a biografia tornaram-

mesmo período que Bourdieu se aproxima das discussões historiográficas em artigos como $O$ morto se apodera do vivo (CHARTIER; LOPES, 2002, p. 157). Michel de Certeau (2011, p. 119) identificaria no método de análise de Bourdieu, partindo do habitus (das normas adquiridas e interiorizadas) para a ação social, uma nova forma de estruturalismo. Para uma resposta às acusações de reducionismo ver Bourdieu (2001). 
| 232 |

Beco sem saída ou ponto de partida?...

se seminais. Ninguém que ouse se aventurar nessa seara pode ignorar mais a ilusão biográfica apontada tão emblematicamente por Bourdieu (e por Cortázar).

\section{Caminhos alternativos}

A apreensão em evidenciar certas informações sobre seus entes queridos, que é patente tanto em Olavo quanto na filha de Suzana Márquez, que retém a prova do caráter pérfido de Romero e do destino incerto de sua mãe, denota a administração da memória dos indivíduos. O que nos coloca uma questão extremamente pertinente, explicitada por Vavy Pacheco Borges (2008, p. 221): "quando começa a nossa história? Nas origens familiares, no nascimento do biografado? E pode a morte ser considerada o final?".

Há um lastro do indivíduo na memória daqueles com quem conviveu, transcendendo sua própria existência. Em Cinzas do Norte isso fica bem nítido. A afetividade, que já era encarada por Maurice Halbwachs (1990, p. 28-29) como um elo poderoso de preservação dos sujeitos na memória, permeia a narrativa de Olavo. Este, reunindo seus relatos com os testemunhos de seu tio e a correspondência do próprio Mundo, realiza uma espécie de vingança contra o esquecimento: seu amigo que nos estertores da vida era menos que uma voz agora é presentificado por um coro de diferentes dicções.

No caso de Romero, embora o interesse da pesquisa nasça da contribuição poética do indivíduo, também há um grão de afetividade no impulso biográfico de Fraga. Ele confessa seu encanto pela vitalidade da obra do artista em certo momento. Isso remete ao que François Dosse considera o primeiro passo para se escrever a vida de alguém. Como ele afirma, "a biografia supõe em geral a empatia, portanto, uma transposição psicológica mais ou menos regulada e dominada - mesmo havendo exceções notórias, como a biografia de Hitler por Ian Kershaw" (DOSSE, 2009, p. 67). 
Após a decisão de escrever sobre uma vida ter sido tomada há o levantamento de dados e com ele a necessidade de organização dessas informações. Sobre esse momento Vavy Pacheco Borges (2008, p. 225) aconselha que o biógrafo faça uso de uma tábua cronológica, independente do resultado narrativo que venha a adotar. A etapa seguinte seria a seleção dos fatos. O biografado move-se no cotidiano, terreno das ações rotineiras. O grau de importância de certas atitudes não é algo explícito. Se o for, corre-se o risco de cometer o mesmo erro de Jorge Fraga.

Nas fontes orais o depoente já oferece um encadeamento causal de fatos que entende como significativos, cabendo ao pesquisador refletir sobre a construção dessa narrativa e com isso também produzir sua interpretação (PORTELLI, 2002). Assim, a vida do biografado terá o sentido que o biógrafo lhe atribuir (BORGES, 2008, p. 221). O narrador principal de Cinzas do Norte atribui um sentido à vida de seu amigo que pode ser vislumbrado na pequena introdução do livro, quando recupera uma frase de Mundo escrita num cartão postal: "ou a obediência estúpida, ou a revolta” (HATOUM, 2010, p. 10).

Embora Tio Ran minimize a eficiência da lei, Olavo, formado em Direito, tenta usá-la em nome da justiça social questionando a "obediência estúpida" aludida por seu amigo. Ele se insere no "sistema" para transformá-lo numa operação quase subterrânea. Trata-se de uma mudança menos radical e visível que aquela preconizada por Mundo, mas ainda assim é uma mudança: “O caso de Macau [agregado da família de Mundo preso injustamente] me fez abandonar o escritório onde começara a trabalhar como estagiário; agora advogava em defesa de detentos miseráveis esquecidos nos cárceres" (HATOUM, 2010, p. 211). Ou seja, a máxima de Mundo ("ou a revolta ou a obediência estúpida") acaba sendo revisitada silenciosamente na própria estrutura narrativa construída por Hatoum.

Cinzas do Norte se assemelha a um modelo que vem conquistando maior atenção recentemente. Giovanni Levi (2002, p. 178) o chama de "biografia hermenêutica", categoria na qual 
a atribuição do sentido biográfico se dá através da relação dialógica estabelecida entre o sujeito pesquisado e o sujeito pesquisador.

Inspirado na obra de Marc Bloch, Paul Ricoeur (1968, p. 25) ajudou a definir os contornos dessa postura ao sugerir que se pense, antes de tudo, que existem múltiplas objetividades e subjetividades, sendo, portanto, necessário que o historiador encontre aquelas que sejam apropriadas às exigências de seu ofício.

O filósofo francês considera a História um setor de intersubjetividade, uma vez que almeja conhecer as pessoas que viveram antes de nós, no entanto, "o encontro em História não é jamais um diálogo, pois a condição primeira do diálogo é que o outro responda" (RICOEUR, 1968, p. 41). A própria dinâmica temporal é uma limitação que se soma à dimensão não-literal de todo discurso (apontada enfaticamente pelos filósofos da linguagem) como condição limitadora de outro propósito da disciplina: atingir a verdade (PESAVENTO, 2003, p. 36).

Diante da incapacidade do próprio texto histórico de representar totalmente o que intenciona representar, o historiador deveria continuar perseguindo a veracidade consciente de que terá como resultado uma narrativa que suscita verossimilhança. Enunciar esse aspecto ficcional da escrita da História não é dizer que o acontecido não tenha de fato acontecido, mas afirmar que no momento em que o pesquisador externa os caminhos que percorreu e as conclusões que chegou ele está construindo também uma narrativa.

De acordo com François Dosse, o biógrafo, tanto quanto o historiador, trabalha entre dois planos: a verdade da ficção e a verdade dos fatos. $\mathrm{O}$ desafio seria não ceder nem a um nem a outro:

O recurso à ficção no trabalho biográfico é, com efeito, inevitável na medida em que não se pode restituir a riqueza e a complexidade da vida real. [...] Procurar trazer tudo à luz é, pois, ao mesmo tempo a ambição 
que orienta o biógrafo e uma aporia que o condena ao fracasso (DOSSE, 2009, p. 55).

Enquanto encadeamento de elementos explicativos ou descritivos, a narrativa nunca esteve ausente das obras dos historiadores, mesmo quando eles procuraram se aproximar do cientificismo (HARTOG, 1998, p. 196). No entanto, só recentemente sua importância foi colocada em pauta. Mas de acordo com Ricoeur, o que torna a História essa, digamos assim, "ficção regulada" é o compromisso com a verdade, vinculando-a as fontes e a um intercâmbio crítico com o Outro. Complementando as reflexões de Ricoeur, Sabina Loriga afirma que

\footnotetext{
poderíamos dizer que o eu do historiador não é uma substância dada, a priori, mas uma aspiração ou mesmo um lugar de trabalho. Para desenvolver uma "boa objetividade", o historiador deve renunciar aos sonhos de ressurreição do passado, aceitar que vive em um terceiro lugar, o qual não coincide nem com o presente, nem com o passado, e reconhecer que a contemporaneidade não é uma condição, um estado, mas uma experiência, inacabada e inacabável, de redução da alteridade (LORIGA, 2012, p. 257).
}

Milton Hatoum em Cinzas do Norte também busca produzir no leitor o mesmo efeito. No entanto, a narrativa de Lavo, costurando lembranças pessoais com as cartas de Tio Ran, assume desde o início ser um exercício de memória. O compromisso com as evidências históricas e com essa "boa objetividade", características que definem o ofício do historiador, pode ser contemplado em alguns exemplos de pesquisas biográficas elencadas por Alexandre de Sá Avelar (2010, p. 165-167): a narrativa multifacetada de Arsênio Frugoni sobre o reformador Arnaud de Brescia, explorando a cada capítulo uma faceta nova do personagem, e as diversas trajetórias de operários de Turim consagradas pela pena de Maurizio Gribaudi, hábil em apresentar tanto as semelhanças quanto as diferenças entre estes homens. 
$|236|$

Beco sem saída ou ponto de partida?..

Por conceber a engenharia da biografia de forma tão orgânica, conciliando objetividade e subjetividade, pesquisa e narrativa, a perspectiva hermenêutica, alicerçada em boa parte nas contribuições de Johann Gustav Droysen e Paul Ricoeur, oferece subsídios para que os historiadores enfrentem o dilema que vem assolando tantos personagens fictícios quanto reais: como escrever sobre a vida de alguém após descobrir a existência de um "novelo de eus". ${ }^{4}$

Porém, o que pode ser visto como a maior força da hermenêutica é também encarada como sua maior fraqueza. Giovanni Levi (2002, p. 178) louva o mérito de enfatizar o diálogo como elemento cognitivo central, mas chama a atenção para certa nebulosidade metodológica que pode ensejar um "relativismo perigoso". Afinal, para ele assim como para muitos a consideração de que "a História faz o historiador tanto quanto o historiador faz a História" (RICOEUR, 1968, p. 34) soou como preocupantemente tautológica.

Convém destacar que propostas para superar a ilusão biográfica têm sido levantadas por nomes tanto dentro quanto fora da corrente hermenêutica. François Dosse (2009, p. 210) cita o exemplo do sociólogo Jean-Claude Passeron, kantiano como o companheiro de pesquisas Bourdieu, mas que enxergava com ressalvas a interdição à biografia. Para Passeron, era possível identificar comportamentos sociais sem anular os sujeitos.

\footnotetext{
${ }^{4}$ Loriga (2012, p. 256), amparando-se na discussão de Daniel Creutz, insinua certa afinidade entre o historiador alemão do século XIX e o filósofo francês do século XX. Ricoeur, que iniciou suas reflexões sobre a objetividade da História na década de 1950, mas tornou-se conhecido dos historiadores após a publicação dos tomos de Tempo e Narrativa em meados dos anos 80, têm sido muito utilizado recentemente como referência capaz de amalgamar polos divergentes no campo historiográfico. Nesse sentido, o que Durval Muniz de Albuquerque Júnior identifica como uma divergência epistemológica insolúvel entre Foucault e Ginzburg pode ser apaziguado por Fernando Nicolazzi (2004), com a ajuda de Ricoeur, enquanto elementos narrativos diferentes, extraindo sua legitimidade não de uma suposta fidelidade à transgressão dos personagens retratados, mas da eficiência em produzir tal efeito no leitor.
} 
Giovanni Levi também partilha dessa convicção ao defender um modelo centrado na capacidade de extração da representatividade dos casos extremos. Ou seja, ele procura explorar na experiência de indivíduos tratados como excêntricos (no sentido de estarem fora de um centro de "normatividade") pelas fontes a "considerável margem de liberdade que se origina precisamente das incoerências dos confins sociais e que suscita a mudança social" (LEVI, 2002, p. 182).

Para o autor, assim como para Carlo Ginzburg (2007, p. 266) o tratamento narrativo é intrínseco à preocupação historiográfica: acompanhar o biografado é procurar entender um contexto social formado por pessoas de carne e osso em oposição à narrativa historiográfica vigente, excessivamente esquemática. Mas acompanhar o biógrafo também é importante:

Os obstáculos postos à pesquisa eram elementos
constitutivos da documentação, logo deviam tornar-
se parte do relato: assim como as hesitações e os
silêncios do protagonista diante das perguntas dos
seus perseguidores - ou das minhas. Desse modo, as
hipóteses, as dúvidas, as incertezas tornavam-se parte
da narração: a busca da verdade tornava-se parte
da exposição da verdade obtida (e necessariamente
incompleta) (GINZBURG, 2007, p. 265).

Apresentar os passos da pesquisa é um importante recurso para incorporar o caráter complexo e provisório do conhecimento histórico a uma biografia, contudo as críticas à Ginzburg e Levi têm recaído sobre a unidade que imputam aos sujeitos por eles pesquisados (ALBUQUERQUE JÚNIOR, 1990, p. 55). Há quem, como Sabina Loriga (2014, p. 255), enxergue em suas obras o feito de "inserir o singular no social" sem desprezar os diversos caminhos do contexto histórico.

Assim, o historiador que deseja ir além da ilusão biográfica tem um espectro considerável de opções em sua frente. Por razões de limitação de espaço, três grandes alternativas foram expostas aqui. $\mathrm{O}$ historiador pode explorar as contradições do biografado 
| 238 |

Beco sem saída ou ponto de partida?...

através das informações oferecidas pelas fontes (como defendia Foucault) ou mesmo analisar a relação entre a experiência do personagem com as condições de sua época (como quer Ginzburg e Levi). O foco maior na alteridade (defendido por Ricoeur) enfatiza o diálogo entre o personagem pesquisado e o pesquisador. Importante deixar claro que para estas alternativas, para umas mais que outras, o senso crítico não deve ser abolido por conta das limitações do conhecimento histórico (no âmbito da subjetividade e da linguagem). Pelo contrário, ele impulsiona a pesquisa a partir delas.

Eis então caminhos que se bifurcam a partir de um mesmo ponto: a certeza da insuficiência dos modelos homogêneos de compreensão da vida individual e social. Caminhos que possuem seus terrenos pantanosos, mas que podem vingar todos aqueles que como Mundo sentiram-se menores que uma voz.

\section{Considerações finais}

Parafraseando a epígrafe deste ensaio, os historiadores, como o poeta amazonense Aldísio Filgueiras, não atinavam para "isso de ser um eu" por um bom tempo. Foi preciso que o edifício da objetividade pura das Ciências Sociais fosse abalado pelas reflexões sobre a construção social da realidade, principalmente através da linguagem, para que pudessem perceber "esse novelo de eus" que cada um de nós carrega. Pioneiramente, a Literatura abordou tal questão dos mais diferentes modos e, mais que isso, enfrentou e tem enfrentado o desafio biográfico, como podemos ver nas obras de Cortázar e Hatoum. No ambiente historiográfico, após o reconhecimento da subjetividade intrínseca da pesquisa e a dimensão inefável da linguagem, as propostas de superação da ilusão biográfica foram poucas. Abordamos aqui ao menos algumas das mais emblemáticas: a análise do indivíduo a partir do emaranhado 
discursivo; a confrontação entre o indivíduo e seu contexto histórico e social; a interpretação do indivíduo por meio de sua relação com a subjetividade do pesquisador. Reconhecê-las como propostas implica numa transformação no sentido da ilusão biográfica para o pesquisador: de beco sem saída a ponto de partida.

\section{Referências}

ALBUQUERQUE JÚNIOR, D. M. Mennochio e Rivière: criminosos da palavra, poetas do silêncio. Revista Resgate, n. 2, v. 2, p. 48-55, dez. 1990.

AVELAR, A. S. A biografia como escrita da História: possibilidades, limites e tensões. Dimensões, v. 24, p. 157-172, 2010.

BORGES, V. P. Grandezas e misérias da biografia. In: PINSKY, C. B. (Org). Fontes Históricas. 2 ${ }^{a}$ ed. São Paulo: Contexto, 2008, p. 203-234.

BOURDIEU, P. A ilusão biográfica. In: AMADO, J. ; FERREIRA, M. de M. (Orgs.). Usos e abusos da história oral. Trad. Glória Rodríguez, Luiz Alberto Monjardim, Maria Magalhães e Maria Carlota Gomes. 5를 ed. Rio de Janeiro: Editora FGV, 2002, p. 183-191.

BOURDIEU, P. Coisas Ditas. Trad. Cássia da Silveira e Denise Pegorim. São Paulo: Brasiliense, 2004.

BOURDIEU, P. Meditações pascalianas. Trad. Sérgio Miceli. Rio de Janeiro: Bertrand Brasil, 2001.

CARVALHO, M. A. S. Julio Florencio se torna Cortázar: o peronismo visto através da Literatura (1945-1956). Dissertação de Mestrado (História) - Universidade Federal Fluminense, 2014.

CERTEAU, M. A invenção do cotidiano: artes de fazer. Trad. Ephraim Ferreira Alves. 17 ${ }^{a}$ ed. Petrópolis: Vozes, 2011.

CHARTIER, R; LOPES, J. S. L. Pierre Bourdieu e a História. Topoi, n. 4, v. 3, p. 139-182, jan-jun. 2002. 
| 240 |

Beco sem saída ou ponto de partida?..

CORTÁZAR, J. Octaedro. Trad. Glória Rodríguez. São Paulo: Companhia Brasileira de Letras, 2011.

CORTÁZAR, J. Valise de cronópio. Trad. Davi Arrigucci Jr. e João Alexandre Barbosa. 2aㅡ ed. São Paulo: Perspectiva, 2006.

DELEUZE, G. Crítica e clínica. Trad. Peter Pál Pelbart. São Paulo: Editora 34, 1997.

DOSSE, F. O desafio biográfico: escrever uma vida. Trad. Gilson César Cardoso de Souza. São Paulo: EDUSP, 2009.

FILGUEIRAS, A. Desastre (menina, cadê minha perna?). In: VIANNA, A.; VIANNA, B. (Orgs.). Manaus 20 autores. Belo Horizonte: Quixote, 2013, p. 19-30.

FOUCAULT, M. A ordem do discurso. Trad. Laura Almeida Sampaio. 5ª ed. São Paulo: Edições Loyola, 1999.

FOUCAULT, M. A verdade e as formas jurídicas. Trad. Roberto Cabral Machado. Rio de Janeiro: NAU Editora, 2005.

FOUCAULT, M. Ditos e escritos. Estética: literatura e pintura, música e cinema. Vol. III. Trad. Inês Autran Dourado. $2^{\underline{a}}$ ed. Rio de Janeiro: Editora Forense, 2009.

FOUCAULT, M. História da Sexualidade II: o uso dos prazeres. Trad. Maria Thereza da Costa Albuquerque. São Paulo: Paz e Terra, 2014.

GAGLIARDI, C. O problema da autoria na teoria literária: apagamentos, retomadas e revisões. Estudos Avançados, v. 24, n. 69, p. 285-299, 2010.

GINZBURG, C. O fio e os rastros. Trad. Rosa Freire D'Aguiar e Eduardo Brandão. São Paulo: Companhia das Letras, 2007.

HALBWACHS, M. A memória coletiva. Trad. Laurent León Schaffter. São Paulo: Editora Vértice, 1990.

HARTOG, F. A arte da narrativa histórica. In: BOUTIER, J. ; JULIA, D. (Orgs.). Passados recompostos: campos e canteiros 
da História. Trad. Marcella Mortara e Anamaria Skinner. Rio de Janeiro: Editora UFRJ/ Editora FGV, 1998, p. 192-201.

HATOUM, M. Cinzas do Norte. São Paulo: Companhia das Letras, 2010.

HATOUM, M. Laços de parentesco: ficção e antropologia. Raízes da Amazônia, vol. 1, n. 1, p. 83-87, Jan. 2005.

LEAL, B. A. Nas trilhas de Milton Hatoum: um breve estudo de uma trajetória intelectual. Dissertação de Mestrado (Sociologia) Universidade Federal do Amazonas, 2010.

LEVI, G. Usos da biografia. In: AMADO, J.; FERREIRA, M. de M. (Orgs.). Usos e abusos da história oral. Trad. Glória Rodríguez, Luiz Alberto Monjardim, Maria Magalhães e Maria Carlota Gomes. 5ª ed. Rio de Janeiro: Editora FGV, 2002, p. 167-182.

LORIGA, S. Nos interstícios da História. Trad. Carla Miussi de Barros. Locus, n. 1, v. 20, p. 251-259, 2014.

LORIGA, S. O eu do historiador. História da Historiografia, n. 10, p. 247-259, dez. 2012.

NICOLAZZI, F. A narrativa da experiência em Foucault e Thompson. Anos 90, v. 11, n. 19, p. 103-131, jan-dez. 2004.

PAES, J. P. O lugar do outro. São Paulo: Topbooks, 1999.

PESAVENTO, S. J. O mundo como texto: leituras da História e da Literatura. História da Educação, n. 14, p. 31-45, set. 2003.

PORTELLI, A. O massacre de Civitella Val di Chiana (Toscana, 29 de Junho de 1944). In: AMADO, J. ; FERREIRA, M. de M. (Orgs.). Usos e abusos da história oral. Trad. Glória Rodríguez, Luiz Alberto Monjardim, Maria Magalhães e Maria Carlota Gomes. 5ª ed. Rio de Janeiro: Editora FGV, 2002, p. 103-130.

RICOEUR, P. História e verdade. Trad. Fernando Ribeiro. Rio de Janeiro: Editora Forense, 1968.

VARGAS LLOSA, M. A morte de Aurora. El País. Disponível em: <http://brasil.elpais.com/brasil/2014/11/13/opinion /1415893327_540070.html>. Acesso em: 22 jan. 2015. 